\title{
OPERATIONAL CHARACTERISTICS OPTIMIZATION OF HUMAN-COMPUTER SYSTEM
}

\author{
ZULQUERNAIN MALLICK ${ }^{1}$, IRFAN ANJUM BADRUDDIN ${ }^{2}$, KHALEED \\ HUSSAIN M.T ${ }^{1}$, SALMAN N JAGIRDAR ${ }^{1}$ \\ ${ }^{1}$ School of Mechanical Engineering, Universiti Sains Malaysia, Penang, MALAYSIA \\ ${ }^{2}$ Dept of Mechanical Engineering, University of Malaya, \\ Kuala Lumpur, 50603 MALAYSIA \\ irfan_magami@Rediffmail.com
}

\begin{abstract}
Computer operational parameters are having vital influence on the operators efficiency from readability viewpoint. Four parameters namely font, text/background color, viewing angle and viewing distance are analyzed. The text reading task, in the form of English text, was presented on the computer screen to the participating subjects and their performance, measured in terms of number of words read per minute (NWRPM), was recorded. For the purpose of optimization, the Taguchi method is used to find the optimal parameters to maximize operators' efficiency for performing readability task. Two levels of each parameter have been considered in this study. An orthogonal array, the signal-to-noise $(\mathrm{S} / \mathrm{N})$ ratio and the analysis of variance (ANOVA) were employed to investigate the operators' performance/efficiency. Results showed that Times Roman font, black text on white background, 40 degree viewing angle and $60 \mathrm{~cm}$ viewing distance, the subjects were quite comfortable, efficient and read maximum number of words per minute. Text/background color was dominant parameter with a percentage contribution of $76.18 \%$ towards the laid down objective followed by font type at $18.17 \%$, viewing distance $7.04 \%$ and viewing angle $0.58 \%$. Experimental results are provided to confirm the effectiveness of this approach.
\end{abstract}

Keywords: Readability, font, text/background color combination, viewing angle, viewing distance, computer workstation.

\section{INTRODUCTION}

The use of visual display unit, with the rapidly increasing pace of computerization in almost every walk of life, has been increasing continuously. With the highly dynamic advances, human computer workstation tasks have greatly increased, as the computer becomes a common platform for the dissemination of information. Thus, it is high time to reexamine and extend the readability research in relation to the presentation of text on this medium. The research on the computer workstation has been carried out since the existence of computer itself. Muter and Mauritto [1] have proposed a study in the same field. Their study demonstrated that reading efficiency from computer screens that were readily available at that time can be equivalent in speed and comprehension to reading from a book. In their experiments, subjects read or skimmed stories, from a high-quality 
cathode ray tube (CRT) and from a book. The results showed that skimming was $41 \%$ slower from the CRTs than from the book. Based on their results it was concluded that reading speed and comprehension were equivalent for the high-quality CRTs and the book and thus, CRTs may eliminate paper.

After a decade people started using computer monitors or video display terminals (VDT) for a wide variety of tasks including reading information. Mayes et al. [2] carried out an experiment to determine if reading information from a VDT resulted in poorer performance. The performance categories tested were reading times, comprehension of the information, and mental workload. It was found that those who read from a VDT took significantly longer time than those reading from paper.

Conventional visual display unit (VDU) is a cathode ray tube (CRT) type. Through technology advances, the liquid crystal display (LCD) monitors have gradually replaced CRTs monitor. However, users' performances on VDTs workstation using CRT monitors display have been reported in the most recent literature. Napflin and Krueger [3] carried out a study on visual performance by using CRT and LCD displays with different levels of ambient light. They found that error frequency for search task carried out using LCD was significantly smaller than the error frequency for tasks performed on CRT. They also observed that the reaction time in search task was significantly shorter using LCD when tasks were performed in darkness. From their experiment they concluded that LCD may give better viewing condition compared to CRT displays. In another study [4], it was found that display screen type had no significant effect on subjects reading performance, however the text/background color combination had a significant effect on reading performance. Lin [5] showed that screen luminance combination significantly affected visual performance. In yet another study, Nasanen and Ojanpaa [6] found that with increasing contrast sharpness, the search time, number of fixations per search and fixation duration first decreased and then became constant at medium levels of contrast or sharpness.

Color combination is another important factor that may affect visual performance. Ling and Schaik [7] investigated the effect of color on the presentation of information in a navigation bar with the objective to contribute towards design guidelines for the use of color on the web. They studied the effect of combination of text and background color on visual search performance and subjective preference. The results of their study showed that higher contrast between text and background color led to faster searching and was rated more favorably. Color can also be an effective way of communication if chosen properly. In recent days it is found that for advertisements and other sorts of information different color combinations are chosen.

Recently, researchers have observed that the text/background color combination had a significant effect on reading performance. It is suggested that a higher difference between text and background color combinations should be maintained for achieving good reading performance. The critical factor in text/background color combination is the luminance contrast between the text and background colors. Shieh and Lin [8] indicated that visual preference increased as the luminance contrast of text/background color combination became greater. 
Shieh and Chen [9] found that screen color combination significantly affected viewing distance, with red text in green background resulting in a shorter viewing distance. Shieh [10] showed that the mean viewing distance for LCD was $42.3 \mathrm{~cm}$ and the viewing distance correlated significantly with subjective visual fatigue i.e. subjects with a longer viewing distance reported less subjective visual fatigue. Jaschinski-Kruza [11-12] showed VDT viewing distance to be correlated with visual strain: fewer feeling of visual fatigue was reported at a viewing distance of $100 \mathrm{~cm}$ than at $50 \mathrm{~cm}$, irrespective of the individual's dark focus. By far two of the most common typefaces currently being used within electronic mediums such as the World Wide Web (Web), are Times New Roman and Arial [13]. There have been a number of reports about the influence of different font styles on reading speed [14-17]. Arditi et al. [14] reported that reading speeds were faster for a Times Roman font with fixed-width spacing compared to proportional spacing for the same font when character size was close to reading acuity limits. Arditi and his coworkers manipulated the inter-character spacing when comparing reading rates for the same font style. The fixed-width spacing was created by adding space around the thinner letters so that each character occupied the same amount of horizontal spaces as the uppercase. Morris et al. [15] using these same fonts, found no difference in reading speed for normally-sighted readers between the fixed or proportionately spaced versions, but the smallest size print measured in their study was $10 \mathrm{~min}$ of visual angle, corresponding to a 20/40 Snellen letter, twice single letter acuity for each subject. Mansfield et al. [16] reported that with letters below critical print size, the smallest print that can be read at maximum reading speed-normals and low vision subjects read the Courier Bold up to twice as fast as the Times font when $\mathrm{x}$-heights were equal. Plass and Yanger [17] reported that, for low-vision subjects, there was no reliable difference in reading speed between Times Roman, a serif font and Arial, a sans serif font, when print was approximately four times single-letter acuity threshold. On the other hand considerable research on positioning the VDT to minimize discomfort and fatigue has been undertaken [18-22]. Despite this effort, 10 million cases of VDT-related eyestrain and physical discomfort are reported to the American Optometric Association each year [23]. Turville et al. [24] reported $40^{\circ}$ VDT position showed significantly greater head tilt angles and higher muscle activity levels for six of the 10 neck, shoulder and back muscles sampled. No significant differences in visual acuity, operator performance or heart rate were detected as a result of monitor location. Seven of 12 subjects preferred the $15^{\circ}$ monitor position.

In view of the above reported findings, an attempt has been made in this paper to optimize operators' efficiency from readability viewpoint by selecting an optimum combination of font, viewing angle, viewing distance, and text/background color combination. For this purpose, the Taguchi method was used and experiments were conducted according to the standard $\mathrm{L}_{8}$ orthogonal array. In the experiments, subjects were asked to read the English text presented on the computer screen at different levels of the above stated four parameters and number of words read per minute (NWRPM) by the subjects was recorded. The NWRPM thus obtained served the data for further analysis. The details of experimental methodology and Taguchi method used for experimentation and data analysis are discussed in the next section. 


\section{METHODOLOGY}

\subsection{Subjects}

Twenty four subjects ( 12 male and 12 female) were recruited from University Science Malaysia. They were right handed and their mean height, weight and age were as presented in Table 1 and Table 2. All participants read English with confidence. All participants had 0.8 correct visual acuity or better and normal color vision. Most participants $(90 \%)$ reported reading from computer regularly.

Table 1: Mean and standard deviation of age, height and weight of subjects participated in the study (Male).

\begin{tabular}{cccccc}
\hline \multicolumn{2}{c}{ Age (yr) } & \multicolumn{2}{c}{ Height (m) } & \multicolumn{2}{c}{ Weight $(\mathrm{kg})$} \\
\hline Mean & SD & Mean & SD & Mean & SD \\
\hline 28.3 & 3.23 & 1.78 & 0.0553 & 60.5 & 6.56 \\
\hline
\end{tabular}

Table 2: Mean and standard deviation of age, height and weight of subjects participated in the study (Female).

\begin{tabular}{cccccc}
\hline \multicolumn{2}{c}{ Age (yr) } & \multicolumn{2}{c}{ Height $(\mathrm{m})$} & \multicolumn{2}{c}{ Weight $(\mathrm{kg})$} \\
\hline Mean & SD & Mean & SD & Mean & SD \\
\hline 27.5 & 2.79 & 1.68 & 0.091 & 55.6 & 4.39 \\
\hline
\end{tabular}

\subsection{Apparatus and VDT Workplace Condition}

The experiment was conducted at the adjustable VDT workstation. Reading text was displayed on a Pentium IV computer using $16 \mathrm{~Hz} 96 \mathrm{dpi} 17 \mathrm{in.} \mathrm{high-resolution} \mathrm{monitor.}$ The resolution of $1024 \times 768$ pixels was chosen in order to reflect trend towards higher resolution setting. The refresh frequencies rate was $85 \mathrm{~Hz}$. The monitor was provided with adjustable brightness and contrast controls. The computer operating system used was Microsoft's XP Professional Windows. The format of the presented text was as HTML web page. The browser used was Microsoft's Internet Explorer 6.0, which was configured to display only the URL address bar.

The light source was located overhead and the level of illumination was monitored through a digital light meter. A digital stop watch was used to record the required for reading the presented text. The metering device was used to measure the distance and the viewing angle between the subject and computer screen. The CRT monitor was positioned on the table $70 \mathrm{~cm}$ in height. The front edge on the table was $30 \mathrm{~cm}$ from the screen center. The inclination angle of the screen for experiment 1 was $180^{\circ}$ with respect to the horizontal axis. All these details are depicted in the schematic diagram of the experimental set up as shown in Fig. 1. 


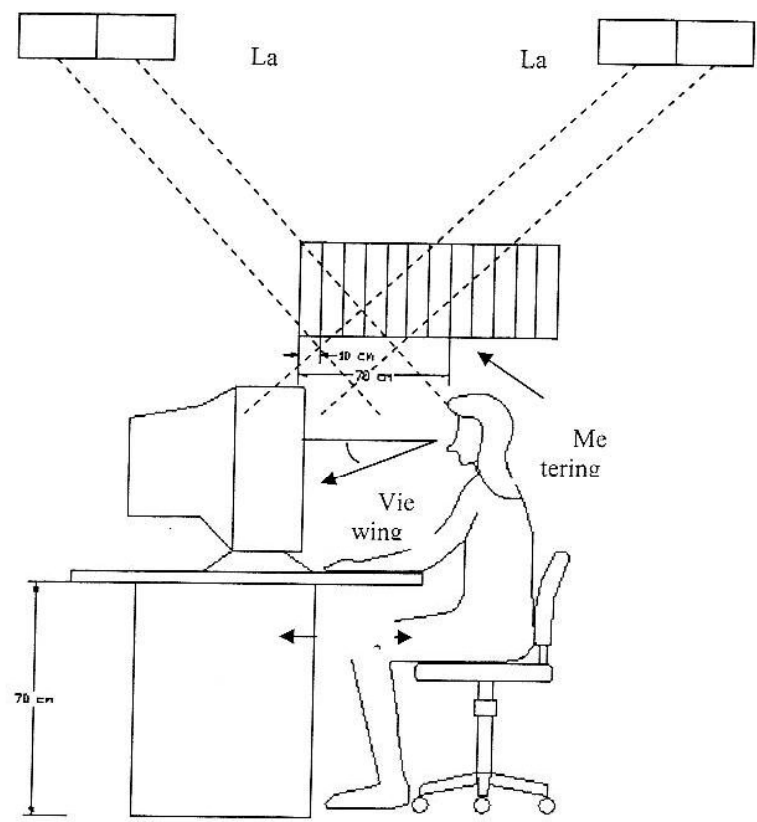

Fig. 1: Schematic diagram of the experimental set up.

\subsection{Task and Procedure}

Subjects were instructed to perform reading task on the computer screen. The paragraphs chosen for reading were saved in the computer memory and according to requirement they were presented to the subjects. In order to ensure that each subject was given equal amount of text for reading, subjects were required to scroll to view the entire page which was approximately 1.5 page screen length. Participants were instructed to scroll through the passage by clicking the down arrow button on the scroll bar as they read. The number of words read by the subjects in specified time was noted down by the experimenter.

\subsection{Selection of Parameters and Their Levels}

The readability performance experiment was carried out in the School of Mechanical Engineering in the computing laboratory under specified parameter conditions i.e. font type, viewing distances, viewing angle and text/background color combinations. The feasible space for the parameters was defined by varying the font style, i.e. Arial and Times Roman, the viewing distance in the range $60-70 \mathrm{~cm}$. Two levels i.e. black text on white background, white text on black background, of the third parameter were selected. 
While the fourth parameter, viewing angle was set at two levels, i.e. 15 degree and 40 degree. Two levels of each parameter were selected as shown in Table 3.

Table 3: Parameters and their levels.

\begin{tabular}{|c|c|c|c|c|}
\hline Parameter & Symbol & Unit & Level 1 & Level 2 \\
\hline Font & $\mathrm{A}$ & - & Arial & Times Roman \\
\hline $\begin{array}{l}\text { Text/background } \\
\text { color }\end{array}$ & B & - & $\begin{array}{c}\text { black text on } \\
\text { white background }\end{array}$ & $\begin{array}{c}\text { white text on } \\
\text { black background }\end{array}$ \\
\hline Viewing angle & $\mathrm{C}$ & degree & 150 & 400 \\
\hline Viewing distance & D & $\mathrm{cm}$ & 60 & 70 \\
\hline
\end{tabular}

\subsection{Determination of Optimal Parameters}

In the following section, the use of an orthogonal array to reduce the number of experiments for design optimization of the parameters is presented. Results of the experiments are studied using the S/N ratio and ANOVA analyses. Based on the results of these analyses, optimal settings of the parameters for number of words read per minute are obtained and verified.

\subsection{Orthogonal Array Experiment}

To select an appropriate orthogonal array for the experiments, the total degrees of freedom need to be determined. The degrees of freedom are defined as the number of comparisons between parameter that need to be determined. For example, a two level design parameter counts for one degree of freedom. The degrees of freedom associated with the interaction between two design parameters are given by the product of the degrees of freedom for the two design parameters. In the present study, the interaction between the parameters is neglected. Therefore, there are four degrees of freedom owing to there being four parameters in the readability task performance.

The degrees of freedom for the orthogonal array should be greater than or at least equal to those for operation parameter. In this study, an $L_{8}$ orthogonal array with four columns and eight rows was used. This array has seven degrees of freedom and it can handle twolevel design parameters. Each parameter is assigned to a column, four-parameter combinations being available. Therefore, only eight experiments are required to study the entire parameter space using the $L_{8}$ orthogonal array. The experimental layout for the four parameters using the $L_{8}$ orthogonal array is shown in Table 4. 
Table 4: Experimental layout using $L_{8}$ orthogonal array.

\begin{tabular}{ccccc}
\hline $\begin{array}{c}\text { Experiment } \\
\text { number }\end{array}$ & \multicolumn{4}{c}{ parameter levels (Level 1 and Level 2) } \\
\cline { 2 - 5 } & A & B & C & D \\
1 & 1 & 1 & 1 & 1 \\
2 & 1 & 1 & 1 & 2 \\
3 & 1 & 2 & 2 & 1 \\
4 & 1 & 2 & 2 & 2 \\
5 & 2 & 1 & 2 & 1 \\
6 & 2 & 1 & 2 & 2 \\
7 & 2 & 2 & 1 & 1 \\
8 & 2 & 2 & 1 & 2 \\
\hline
\end{tabular}

\subsection{Data Collection}

Before starting the actual experiment, a trial experiment was performed to familiarize the participants the way they will perform the readability task. Eight experiment as per the plan shown in Table 4 was performed. Each experiment was repeated three times by employing three subjects and number of words read per minute by them was obtained. The overall experimental results are shown in Table 5.

Table 5: Experimental result for readability performance and $\mathrm{S} / \mathrm{N}$ ratio.

\begin{tabular}{ccccccc}
\hline No. & $\begin{array}{c}\text { Font } \\
\text { style } \\
\text { (A) }\end{array}$ & $\begin{array}{c}\text { Text/background } \\
\text { color (B) }\end{array}$ & $\begin{array}{c}\text { Viewing } \\
\text { angle (C) }\end{array}$ & $\begin{array}{c}\text { Viewing } \\
\text { distance(D) }\end{array}$ & $\begin{array}{c}\text { Mean number of } \\
\text { words read per } \\
\text { minute }\end{array}$ & $\begin{array}{c}\text { S/N } \\
\text { Ratio }\end{array}$ \\
\hline 1 & 1 & 1 & 1 & 1 & 212.04 & 46.52 \\
2 & 1 & 1 & 1 & 2 & 206.33 & 46.29 \\
3 & 1 & 2 & 2 & 1 & 225.91 & 47.07 \\
4 & 1 & 2 & 2 & 2 & 223.75 & 46.99 \\
5 & 2 & 1 & 2 & 1 & 219.29 & 46.82 \\
6 & 2 & 1 & 2 & 2 & 215.37 & 46.66 \\
7 & 2 & 2 & 1 & 1 & 231.16 & 47.27 \\
8 & 2 & 2 & 1 & 2 & 230.62 & 47.25 \\
\hline
\end{tabular}




\section{RESULTS AND DISCUSSION}

The Taguchi method uses the $\mathrm{S} / \mathrm{N}$ ratio to measure the quality characteristics deviating from the desired value. In the Taguchi method, the term signal represents the desirable value (mean) for the output characteristics. Therefore, the $\mathrm{S} / \mathrm{N}$ ratio is the ratio of the mean to standard deviation. The $\mathrm{S} / \mathrm{N}$ ratio, defined as:

$$
\eta=-10 \log (M . S . D .)
$$

where M.S.D. is the mean-square deviation for the output characteristic.

There are three categories of performance characteristics, i.e. the-lower-the-better, thehigher-the-better, and the-nominal-the-better. To obtain the higher readability performance, the higher the better characteristics for readability performance should be taken. The M.S.D. for the higher the better quality characteristics can be expressed as:

$$
\text { M.S.D. }=\frac{1}{m} \sum_{i=1}^{m} R_{i}^{2}
$$

Where $m$ is the number of tests and $R_{i}$ is the value of number of words read per minute for the $i$ th test.

The S/N ratio for the eight experiments was calculated using Eqs. (1) and (2) and the results are shown in Table 5. Since the experimental design is orthogonal, it is then possible to separate out the effect of each parameter at different levels. For example, the mean $\mathrm{S} / \mathrm{N}$ ratio for the type of font at levels 1 and 2 can be calculated by averaging the $\mathrm{S} / \mathrm{N}$ ratio for the experiments $1-2,3-4,5-6$ and $7-8$, respectively. The mean S/N ratio for each level of the other parameters can be computed in the similar manner. The mean $\mathrm{S} / \mathrm{N}$ ratio for each level of the computer operational parameters is summarized in Table 5 . In addition, the total mean $\mathrm{S} / \mathrm{N}$ ratio for the eight experiments is also calculated and listed below Table 5 .

Figure 2 shows the $\mathrm{S} / \mathrm{N}$ response graph for the output characteristic (number of words read per minute). As shown in Eqs. (1) and (2), the greater the S/N ratio, the smaller is the variance of the output characteristic around the desired (the-higher-the-better) value. However, the relative importance amongst the parameters still needs to be known so that optimal combinations of the parameter levels can be determined more accurately. This will be discussed in the next section using the analysis of variance.

\subsection{Analysis of Variance (ANOVA)}

The purpose of the analysis of variance (ANOVA) is to investigate which parameters significantly affect the performance characteristic. This is accomplished by separating the total variability of the $\mathrm{S} / \mathrm{N}$ ratios, which is measured by the sum of squared deviations from the total mean $\mathrm{S} / \mathrm{N}$ ratio, into contributions by each of the design parameters and the 
error. First, the total sum of squared deviations $\mathrm{SS}_{\mathrm{T}}$ from the mean $\mathrm{S} / \mathrm{N}$ ratio $\eta_{\mathrm{m}}$ is calculated as:

$$
\mathrm{SS}_{\mathrm{T}}=\sum_{i=1}^{n}\left(\eta_{i}-\eta_{\mathrm{m}}\right)^{2}
$$

where $n$ is number of experiments in the orthogonal array, $\eta_{i}$ is the mean $\mathrm{S} / \mathrm{N}$ ratio for the $i$ th experiment.

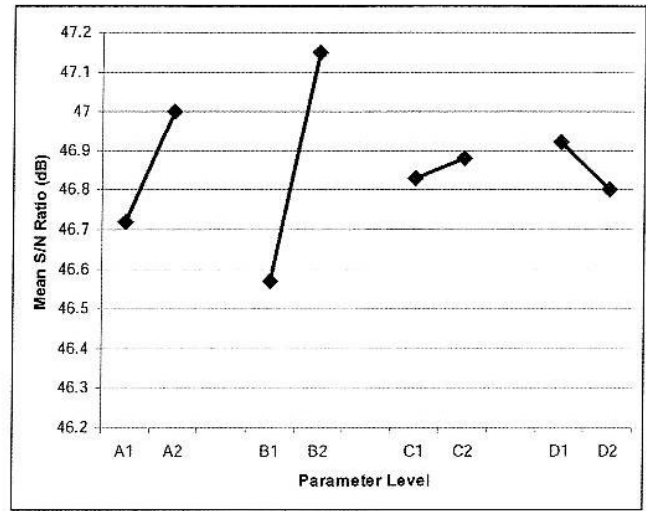

Fig. 2: S/N graph for the number of words read per minute (NWRPM).

The total sum of squared deviations $\mathrm{SS}_{\mathrm{T}}$ is decomposed into two sources: the sum of squared deviations $\mathrm{SS}_{\mathrm{d}}$ due to each process parameter and the sum of squared error $\mathrm{SS}_{\mathrm{e}}$. The percentage contribution $p$ by each of the process parameter in the total sum of squared deviations $\mathrm{SS}_{\mathrm{T}}$ is a ratio of the sum of squared deviations $\mathrm{SS}_{\mathrm{d}}$ due to each process parameter to the total sum of squared deviations $\mathrm{SS}_{\mathrm{T}}$.

Statistically, there is a tool called $F$ test to see which process parameters have significant effect on the quality characteristic. For performing the $F$ test, the mean of squared deviations $\mathrm{SS}_{\mathrm{m}}$ due to each process parameter needs to be calculated. The mean of squared deviations $\mathrm{SS}_{\mathrm{m}}$ is equal to the sum of squared deviations $\mathrm{SS}_{\mathrm{d}}$ divided by the number of degrees of freedom associated with the process parameter. Then, the $F$ value for each process parameter is simply the ratio of the mean of squared deviations $\mathrm{SS}_{\mathrm{m}}$ to the mean of squared error $\mathrm{SS}_{\mathrm{e}}$.

Table 7 shows the results of analysis of variance. The $\mathrm{F}$ - ratios were obtained for $99 \%$ level of confidence. In addition to this percentage contribution of each parameter was also calculated. It can be seen from Table 6 that readability task performance, within the range investigated as shown in Table 3 , two parameters i.e. text/background color combination and font style were significant in terms of affecting the readability task performance resulting in maximum number of words read per minute. However, viewing distance and viewing angle does not have any significant effect on readability task performance of 
operators. However, based on the results of $\mathrm{S} / \mathrm{N}$ ratio analysis the optimal parameters are the font style at level 2, the text/background color combination at level 2, viewing angle at level 2 and viewing distance at level 1. It can also be seen from Table 6 that each parameter contributes to the quality characteristics (maximum number of words read per minute). The contribution of four parameters i.e text/background colour combination, font style, viewing distance and viewing angle is shown in Figure 3.

Table 6: $\mathrm{S} / \mathrm{N}$ response table for readability performance.

\begin{tabular}{ccccc}
\hline Symbol & Parameters & \multicolumn{3}{c}{ Mean S/N ration (dB) } \\
\cline { 3 - 5 } & & Level 1 & Level 2 & Max-min \\
& & 46.72 & 47.00 & 0.28 \\
A & Font style & 46.57 & 47.15 & 0.58 \\
B & Text/background color & 46.83 & 46.88 & 0.05 \\
C & Viewing angle & 46.92 & 46.80 & 0.12 \\
D & Viewing distance & 4 \\
\hline
\end{tabular}

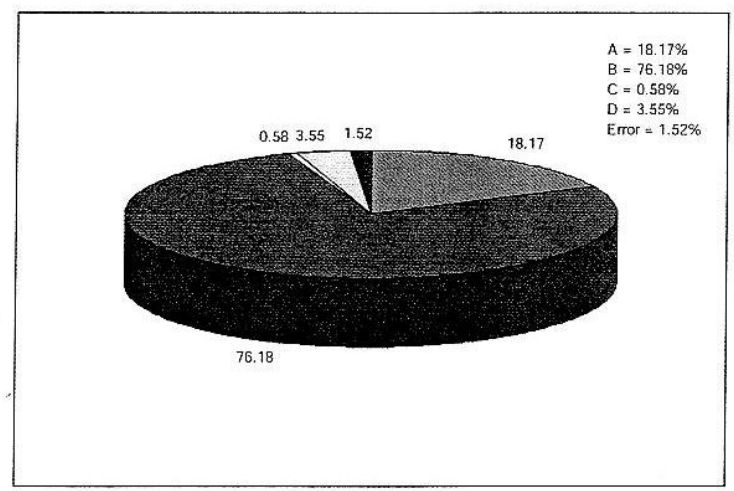

Fig. 3: Pie chart showing percentage contribution of the parameters.

It is evident from the results that the text/background color contributes the most to the readability performance. It was found that the task performance was more significant for higher text/background color compare with lower text/background, which is in conformity to the results obtained by Wang and Chen [4]. Shieh and Lin [8] also indicated that visual identification performance and subjective preference increased as the luminance contrast of text/background color combination became greater.

\subsection{Confirmation Test}

Once the optimal combination and level of parameters for maximum readability performance in terms of number of words read per minute has been obtained, the final step was to verify the estimated results against the experimental values. Estimated readability performance at optimum condition was calculated by adding the average performance to the contribution of each parameter. Table 7 shows the comparison of the predicted 
readability performance with the experimental readability performance using the optimal operating parameters. The difference of the $\mathrm{S} / \mathrm{N}$ ratio is only $0.40 \mathrm{~dB}$, between predicted and experimental value. In other words, the experiment results confirm the prior design and analysis for optimizing the parameters.

Table 7: Result of the analysis of variance for the readability performance.

\begin{tabular}{ccccccc}
\hline Symbol & Parameters & $\begin{array}{c}\text { Degrees } \\
\text { of } \\
\text { freedom }\end{array}$ & $\begin{array}{c}\text { Sum of } \\
\text { square }\end{array}$ & $\begin{array}{c}\text { Mean } \\
\text { square }\end{array}$ & F & $\begin{array}{c}\text { Contribution } \\
(\%)\end{array}$ \\
\hline A & Illumination level & 1 & 0.1587 & 0.1587 & 36.06 & 18.17 \\
B & Viewing distance & 1 & 0.6651 & 0.6651 & 151.99 & 76.18 \\
C & Text/background & 1 & 0.0051 & 0.0051 & 1.15 & 0.58 \\
& color & 1 & 0.0310 & 0.0310 & 7.04 & 3.55 \\
D & & 3 & 0.0131 & 0.0044 & & 1.52 \\
\multicolumn{2}{c}{ All other/Error } & 7 & 0.8730 & 0.8643 & 196.24 & 100 \\
\hline
\end{tabular}

\section{CONCLUSION}

This paper has presented a study to investigate the effect of four important parameters i.e. font style, viewing distance, text/background color combination and viewing angle, under which the readability kind of task is performed on a computer screen. Subsequently, the optimum levels of these parameters for maximizing the reading efficiency of the operators (measured in terms of number of words read per minute) are found using the Taguchi method. As shown in this study, the Taguchi method provides a systematic and efficient methodology for getting optimum levels of the parameter with far less effect than would be required for most optimization techniques. From the results, it has been found that within the range of the parameters investigated in this study, font style i.e. Times Roman, viewing angle of $40^{\circ}$, a combination of black text on white background and viewing distance $60 \mathrm{~cm}$ yield maximum efficiency of the computer operators for a readability task. It is also found that the text/background color is the dominant parameter and its percentage contribution towards achieving maximum reading efficiency is $76.18 \%$, followed by font style at $18.17 \%$, viewing distance at $3.55 \%$ and viewing angle at $0.58 \%$. The confirmation experiments were conducted to verify the optimal parameters.

\section{REFERENCES}

[1] P. Muter and P. Mauritto, "Reading and skimming from computer screens and books: the paperless office revisited?", Behaviour \& Information Technology, Vol. 10, No.4, pp. 257266. 1991,

[2] D.K Mayes, V.K Sims, J. Koonce,, "Comprehension and workload differences for VDT and paper-based reading", International Journal of Industrial Ergonomics, Vol. 28, pp. 367-378. 2001. 
[3] M .U. Napflin, H. Krueger, "CRT versus LCD: A pilot study on visual performance and suitability of two display technologies for use in office work", Displays, Vol. 20, pp. 310.1999.

[4] C.C.Lin, , "Effects of screen luminance combination and text color on visual performance with TFT-LCD”, International Journal of Industrial Ergonomics, Vol. 35, pp. 229-235.2005.

[5] A.H. Wang, C.H Chen, "Effects of screen type, Chinese Typography, tex/background color combination, speed, and jump length for VDT leading display on users' reading performance", International Journal pf Industrial Ergonomics, Vol. 31, pp. 249-261. 2003.

[6] R.Nasanen, ,H. Ojanpaa, "Effect of image contrast and sharpness on visual search fof computer icons."Display, Vol. 24, pp. 167-178.2000.

[7] J.Ling, ,P.V Schaik, "The effect of text and background colour on visual search of Web pages", Displays, Vol. 23, pp. 223-230.2002.

[8] K.K Shieh, ,C.C Lin, "Effects of screen type, ambient illumination, and color combination on VDT visual performance and subjective preference", International Journal of Industrial Ergonomics, Vol. 26, pp. 527-536.2002.

[9] K.K.Shieh, ,M.T Chen, "Effect of screen color combination, work-break schedule, and workplace on VDT viewing distance", International Journal of Industrial Ergonomics, Vol.20, pp11-18.2000.

[10] K.K Shieh, "Effects of reflection and polarity on LCD viewing distance." International Journal of Industrial Ergonomics, Vol. 25, pp275-282.2000.

[11] W.Jaschinski-Kruza, , . Visual strain during VDU work: The effect of Viewing distance and dark focus. Ergonomics 31, 1449-1465.1988.

[12] W.Jaschinski-Kruza, On the preferred viewing distances to screen and Document at VDU workplaces. Ergonomics 33, 1055-1063.1990.

[13] A.Ramsden Annabella's HTML help.From: http://www.geocities.com/annabella.geo/fontface.html. 2001

[14] A.Arditi ,K. Knoblauch ,I. Grunwald, "Reading with fixed and variable pitch." J Opt Soc Am A ; 7: 2011-5.1990.

[15] R.A.Morris , K.Berry , K.A Hargreaves , D. Liarokapis . " How typeface variation and typographic scaling affect readability at small sizes". Society for Imaging Science and Technology, Portland: Proceeding of the $7^{\text {th }}$ International Congress on Advances in Nonimpact Printing Technologies, 1991.

[16] J.S.Mansfield ,G.E. Legge , Bane MmC. "Psychophysics of reading XV: Font effects in normal and low vision. Invest Ophthalmol Vis Sci. ; 37:1492-2015.1996

[17] R.Plass, and D. Yager . "Presentation of video-based text to low vision readers: Rapid serial visual presentation vs. full-page reading". Invest Ophthalmol Vis Sci 1995; 36:S71.

[18] R.Arndt, "Working posture and musculoskeletal problems of video display terminal operators-review and reappraisal". Am Ind Hyg Assoc J. 44 (6) 437-446.1983.

[19] W.Jaschchinski-Kruza, "Eyestrain in VDU user: viewing distances and the resting position of the ocular muscles". Human Factors. 33, 69-83.1993.

[20] CWL Pickett and REM Lees. "A cross-sectional study of health complaints among 79 data entry operators using video display terminals". Occup Med 41, 113-116.1991.

[21] S.L.Sauter ,L.M. Schliefer and S.J. Knutson. "Work posture, workstation design, and musculoskeletal discomfort in a VDT data entry task. Human Factors, 33, 151-167. 1991. 
[22] M.B.G.Villanueva ,M. Sotoyama ,H. Jonai ,Y.Takeuchi and S.Saitu "Adjustment of posture and viewing parameters of the eye to changes in the screen height of the visual display terminal". Ergonomics, 39(7) 933-945.1996.

[23] S.B.Leavitt "Lower your VDT monitor workplace". Ergonomics July/August, 32-35.1995.

[24] K.LTurville , J.P. Psihogios ,T.R Ulmer, G.A Marika . "The effects of video displsy terminal height on the operator: a comparison of the $15^{\circ}$ and $40^{\circ}$ recommendations". Applied Ergonomics, Vol 29, No 4, pp 239-246.1998 